\title{
Novel molecular markers of Chlamydia pecorum genetic diversity in the koala (Phascolarctos cinereus)
}

\author{
James Marsh, Avinash Kollipara, Peter Timms and Adam Polkinghorne*
}

\begin{abstract}
Background: Chlamydia pecorum is an obligate intracellular bacterium and the causative agent of reproductive and ocular disease in several animal hosts including koalas, sheep, cattle and goats. C. pecorum strains detected in koalas are genetically diverse, raising interesting questions about the origin and transmission of this species within koala hosts. While the ompA gene remains the most widely-used target in C. pecorum typing studies, it is generally recognised that surface protein encoding genes are not suited for phylogenetic analysis and it is becoming increasingly apparent that the ompA gene locus is not congruent with the phylogeny of the C. pecorum genome. Using the recently sequenced C. pecorum genome sequence (E58), we analysed 10 genes, including ompA, to evaluate the use of ompA as a molecular marker in the study of koala C. pecorum genetic diversity.

Results: Three genes (incA, ORF663, tarP) were found to contain sufficient nucleotide diversity and discriminatory power for detailed analysis and were used, with ompA, to genotype 24 C. pecorum PCR-positive koala samples from four populations. The most robust representation of the phylogeny of these samples was achieved through concatenation of all four gene sequences, enabling the recreation of a "true" phylogenetic signal. OmpA and incA were of limited value as fine-detailed genetic markers as they were unable to confer accurate phylogenetic distinctions between samples. On the other hand, the tarP and ORF663 genes were identified as useful "neutral" and "contingency" markers respectively, to represent the broad evolutionary history and intra-species genetic diversity of koala C. pecorum. Furthermore, the concatenation of ompA, incA and ORF663 sequences highlighted the monophyletic nature of koala C. pecorum infections by demonstrating a single evolutionary trajectory for koala hosts that is distinct from that seen in non-koala hosts.

Conclusions: While the continued use of ompA as a fine-detailed molecular marker for epidemiological analysis appears justified, the tarP and ORF663 genes also appear to be valuable markers of phylogenetic or biogeographic divisions at the C. pecorum intra-species level. This research has significant implications for future typing studies to understand the phylogeny, genetic diversity, and epidemiology of C. pecorum infections in the koala and other animal species.
\end{abstract}

\section{Background}

Chlamydia are obligate intracellular bacterial pathogens that are characterised by a biphasic development cycle, involving the inter-conversion between an extracellular, metabolically inert form (elementary body, EB) and an intracellular, metabolically active form (reticulate body, RB) [1]. With the advent of molecular analyses, the taxonomy of chlamydiae has undergone several revisions [2], with a recent proposal recognising nine species within the Chlamydia genus: C. trachomatis, C. muridarum,

\footnotetext{
* Correspondence: a.polkinghorne@qut.edu.au

* Correspondence: a.polkinghorne@qut.edu.au
Institute of Health and Biomedical Innovation, Queensland University of Technology, Brisbane, Australia
}

C. caviae, and C. pecorum [3-5]. For the purpose of this research paper, we will refer to koala C. pecorum strains using this proposed nomenclature. While each of these are responsible for a number of disease states in a wide range of animals (including humans), the prevalence and transmission of C. pneumoniae and C. pecorum throughout Australian koala populations has contributed to a significant decline in koala numbers and remain a critical threat to the koala's continued survival [6-8].

C. pneumoniae and C. pecorum have been isolated from most koala populations investigated, with C. pecorum found to be the most widespread and pathogenic of the 
two species [7-10]. Notably, C. pecorum is also recognised as a pathogen and causative agent of polyarthritis and abortion in sheep and cattle [11]. In the koala, clinical manifestations of $C$. pecorum include ocular infection leading to conjunctival scarring and blindness, respiratory tract infection, urinary tract infection causing incontinence, and genital tract infection potentially leading to infertility $[6,7,12-14]$. The latter disease signs have been implicated in lowered reproductive rates in wild koala populations in several parts of Australia, highlighting the need to understand this complex host-parasite relationship for the purpose of effective management and control strategies [8].

Questions remain about the evolutionary origin of C. pecorum in koalas, given its traditional role as a pathogen of sheep and cattle, and the modes of transmission within and between geographically isolated koala populations. In an attempt to understand these questions, Jackson et al., have previously performed fine-detailed epidemiological surveys of C. pecoruminfected koala populations, revealing that $C$. pecorum is genetically very diverse [7]. This analysis was performed on short variable domain IV (VDIV) sequence fragments of the ompA gene, encoding the surface-exposed major outer membrane protein (MOMP) which is common to all members of the Chlamydiaceae [15]. There are currently eight ompA VDIV genotypes that have been identified, following several studies of geographically isolated koala populations in Australia [7,8,14,16,17]. While the majority of these genotypes are apparently confined to the koala host, several identical or near-identical sequences have been found in European sheep and cattle implying the possibility of cross-species transmission events between these hosts [7].

Questions, however, remain regarding the use of ompA as a single gene marker of chlamydial diversity. From a phylogenetic perspective, previous studies in other chlamydial species have demonstrated that ompA phylogenies are not congruent with the phylogeny of other gene targets, including other membrane proteins [18-20]. Similar observations have also been made for non-koala strains of C. pecorum [11,21], indicating that C. pecorum ompA gene phylogenies are not congruent with the phylogeny of other targets, nor are they compatible with groupings based on tissue tropisms or pathobiological profiles. Diversifying host immune pressure is hypothesised to cause the C. pecorum ompA gene to evolve more rapidly than the rest of the chlamydial genome, rendering it incapable of reflecting the true evolutionary divergence of C. pecorum [11].

Until recently, the use of alternate molecular markers for the genetic analysis of koala $C$. pecorum has been limited due to the lack of DNA sequences for this species. However, the recent completion of the currently unpublished
C. pecorum genome sequence from the E58 type strain is allowing investigation into novel and alternative gene targets. Most notably, Yousef Mohamad et al. recently identified several genes that were potentially useful as C. pecorum markers of virulence and pathogenicity [21]. In the current study, we have utilised the C. pecorum E58 strain genome sequence in the preliminary characterisation of 10 novel gene targets for the purpose of validating omp $\mathrm{A}$ as a fine-detailed genetic and phylogenetic marker for $C$. pecorum infections in the koala.

The primary objectives of the present study were to apply our selected genes to (1) a determination of the number of major phylogenetic divisions within koala C. pecorum samples obtained from four distinct koala populations; (2) the identification of useful fine-detailed genetic markers to represent these phylogenetic divisions; and (3) a reconstruction of the evolutionary history of lineage divergence between koala and non-koala hosts of C. pecorum. Overall, this study identifies useful alternative tools for the future characterisation of koala C. pecorum infections. Additionally, we present a preliminary appreciation of the phylogenetic diversity of C. pecorum in koala and non-koala hosts, as a prelude to future in-depth multi-locus sequence typing (MLST) studies of the C. pecorum phylogeny.

\section{Methods}

\section{Chlamydial strains and clinical samples}

The 'type strain' (MC/MarsBar) utilised for C. pecorum gene sequencing and analysis was recently isolated and cultured in our laboratory from a female koala suffering severe genital tract and ocular disease with chronic cystitis. The sample originated from Mount Cotton in South-East Queensland. Swab samples collected from wild koalas were stored at $-80^{\circ} \mathrm{C}$ prior to DNA extraction.

\section{Selection of candidate molecular marker genes}

A total of 10 genes were selected as candidate marker genes, including two housekeeping genes to serve as analysis controls, five membrane proteins and three potential virulence genes. The gene candidates included: $16 \mathrm{~S}$ rRNA: A housekeeping gene that forms the $16 \mathrm{~S}$ ribosomal unit; 16S-23S intergenic spacer: A non-transcribed spacer between $16 \mathrm{~S}$ and $23 \mathrm{~S}$ ribosomal sequences [22]; ompA: Encodes the major outer membrane protein (MOMP) protein, a porin responsible for nutrient transfer, attachment and structural support [23]; omcB: A cysteine-rich outer membrane polypeptide with functional, structural, and antigenic properties [24]; pmpD: A polymorphic membrane protein and putative autotransporter peptide [25]; incA: Encodes an inclusion membrane protein engaged in the interactions between the chlamydial inclusion and cytosolic components [26]; $\operatorname{cop} \mathrm{N}$ : A virulence-related Type III secretion effector [27]; 
tarP: A translocated actin-recruiting phosphoprotein that recruits actin at the site of internalisation [28]; MACPF: The membrane attach complex/perforin protein and a predicted virulence gene [29]; and ORF663: A hypothetical protein gene whose function is currently unknown [21]. Overall these genes are functionally diverse and are widely distributed around the C. pecorum chromosome (data not shown).

\section{Primers, PCR amplification and sequencing}

Primers were primarily based on C. pecorum E58 gene sequences. To ensure regions of sufficient sequence conservation were targeted, analyses of homologous gene sequences available from other published chlamydial genomes, including C. trachomatis, C. pneumoniae, C. caviae, C. felis, C. muridarum, and C. abortus (Table 1), were also performed.

Amplification of novel gene sequences from our C. pecorum koala type strain began with the addition of $100 \mathrm{ng}$ of semi-purified MC/MarsBar to a PCR mixture containing $1 \mathrm{X}$ ThermoPol reaction buffer, $0.2 \mathrm{mM}$ deoxynucleotide triphosphates (Roche), $1 \mathrm{pmol} / \mu \mathrm{L}$ each primer (Sigma; Table 2), and $2 \mathrm{U} \mathrm{Vent}_{\mathrm{R}}{ }^{\circledR}$ DNA polymerase (New England Biolabs). PCR conditions were a single cycle of initial denaturation at $94^{\circ} \mathrm{C}$ for 2 minutes, 30 cycles of denaturation at $94^{\circ} \mathrm{C}$ for 1 minute, primer annealing for 1 minute (Table 2), primer extension at $72^{\circ} \mathrm{C}$ for 2 minutes followed by a final elongation step at $72^{\circ} \mathrm{C}$ for 10 minutes.

Due to the low quality and quantity of template from the koala clinical samples, an alternate PCR protocol was adopted which was optimised for higher specificity and sensitivity. This was achieved by the addition of $5 \mu \mathrm{L}$ of DNA extracted from C. pecorum-positive swab samples to a PCR mixture containing $1 \mathrm{X}$ AmpliTaq Gold $36010 \times$ buffer, $0.2 \mathrm{mM}$ of each deoxynucleotide triphosphate (Applied Biosystems), $1 \mathrm{pmol} / \mu \mathrm{L}$ each primer (Sigma; Table 2), and 1 U AmpliTaq Gold 360 DNA polymerase ${ }^{\mathrm{TM}}$ (Applied Biosystems). PCR conditions were a single cycle of initial denaturation at $95^{\circ} \mathrm{C}$ for 10 minutes, 45 cycles of denaturation at $95^{\circ} \mathrm{C}$ for 1 minute, primer annealing for 1 minute (Table 2), primer extension at $72^{\circ} \mathrm{C}$ for 1 minute, followed by a final elongation step at $72^{\circ} \mathrm{C}$ for 7 minutes.

PCR products for both assays were separated by gel electrophoresis and visualised using a UV transmilluminator. Negative controls $\left(\mathrm{dH}_{2} \mathrm{O}\right)$ were included in each amplification round to control for PCR contamination. PCR products were purified with an Invitrogen PureLink ${ }^{\text {TM }}$ PCR purification kit and sent to the Australian Genome Research Facility (AGRF) for sequencing using the Sanger dideoxy method [30]. Gene sequence names from each C. pecorum positive sample were derived from the population from which the koala originated and the ID name assigned by the veterinarians (i.e. 'Bre/Ned' = Brendale population; animal name 'Ned').

\section{Sequence and statistical analysis}

Alignments for each sequenced gene were produced using ClustalW [31] and RevTrans [32] was used to reverse-translate all alignments. Non-coding genes were aligned based on their nucleotide sequence.

The software package DnaSP 5.0 [33] was used to analyse the extent of sequence variation by calculating the number of polymorphic and parsimony-informative sites, the average nucleotide diversity ( $p$-distance) and Tajima's test for neutrality ( $D$-value). The Molecular Evolutionary Genetics Analysis (MEGA) [34] software package was used to calculate the number of synonymous and non-synonymous sites and subsequent $\mathrm{d} N /$ $\mathrm{d} S$ ratio using the Nei-Gojobori method [35]. The discrimination index (D.I.), based on Simpson's index of diversity [36], was calculated to determine the differentiating and discriminatory capacity of each gene:

$$
D=1-\left[\{1 / N(N-1)\} \times \sum n_{\mathrm{i}}\left(n_{\mathrm{i}}-1\right)\right]
$$

where $D=$ index of discrimination, $N=$ number of strains in the sample, and $n_{\mathrm{i}}=$ number of strains in group i. The index ranges from 0 to 1 , with a value close to 0 indicating low genetic diversity and a value close to 1 indicating high genetic diversity [36]. Calculation of the D.I. requires at least three nucleotide sequences for analysis.

\section{Criteria for identifying genetic markers}

In order to select the most appropriate candidate genes for further investigation, a shortlist of three genes, ORF663, inc A and $\operatorname{tar} \mathrm{P}$ (in addition to ompA), were selected based on their application in previous $C$. pecorum typing studies [21], in addition to several empirical criterions: The average proportion of nucleotide distances ( $p$-distance) should be $\geq 0.02$ before intra-species differentiation may be attempted [37,38], which can be calculated from an alignment containing two or more sequences $[39,40]$. Furthermore, both highly constrained, slowly-changing molecular markers and highly variable genes under diversifying selection each have their advantages, disadvantages, and advocates [41], implying the importance of selecting genes under both positive and negative selection. Finally, the discrimination index (D.I.) for candidate markers should be $>0.50$, which is suggested to be sufficient discriminatory power for adequate differentiation of bacteria beyond the species level [42-44].

\section{Koala populations, swab collection and processing}

Four distinct Australian koala populations were studied: East Coomera, Brendale, Narangba, and Pine Creek. The 
Table 1 Chlamydial sequences analysed in this study

\begin{tabular}{|c|c|c|c|c|c|}
\hline Species & Strain & Origin & Host & Pathology & Sequence reference \\
\hline C. abortus & $S 26 / 3$ & Scotland & Sheep & Abortion & {$[62]$} \\
\hline C. caviae & GPIC & USA & Guinea Pig & Conjunctivitis & {$[63]$} \\
\hline C. felis & $\mathrm{Fe} / \mathrm{C}-56$ & Japan & Cat & Pneumonia & {$[64]$} \\
\hline C. muridarum & Nigg & USA & Mouse & Pneumonia & {$[65]$} \\
\hline C. pecorum & 824 & Scotland & Sheep & Conjunctivitis & {$[21]$} \\
\hline C. pecorum & $A B 10$ & France & Sheep & Abortion & {$[21]$} \\
\hline C. pecorum & AKT & Tunis & Sheep & Abortion & {$[21]$} \\
\hline C. pecorum & BE53 & England & Cattle & Encephalymylitis & {$[21]$} \\
\hline C. pecorum & E58 & USA & Cattle & Encephalomylitis & {$[21]$} \\
\hline C. pecorum & iB1 & France & Sheep & Healthy (faeces) & {$[21]$} \\
\hline C. pecorum & iB2 & France & Sheep & Healthy (faeces) & {$[21]$} \\
\hline C. pecorum & iB3 & France & Sheep & Healthy (faeces) & {$[21]$} \\
\hline C. pecorum & iB4 & France & Sheep & Healthy (faeces) & {$[21]$} \\
\hline C. pecorum & iB5 & France & Sheep & Healthy (faeces) & {$[21]$} \\
\hline C. pecorum & $\mathrm{iC2}$ & France & Goat & Healthy (faeces) & [21] \\
\hline C. pecorum & $\mathrm{iC3}$ & France & Goat & Healthy (faeces) & [21] \\
\hline C. pecorum & iC4 & France & Goat & Healthy (faeces) & [21] \\
\hline C. pecorum & LW679 & USA & Sheep & Arthritis & {$[21]$} \\
\hline C. pecorum & M14 & Morocco & Goat & Abortion & {$[21]$} \\
\hline C. pecorum & MC/MarsBar & Australia & Koala & Genital tract infection & (this work) \\
\hline C. pecorum & R69 & Ireland & Sheep & Healthy (faeces) & [21] \\
\hline C. pecorum & SBE & England & Cattle & Encephalomylitis & {$[21]$} \\
\hline C. pecorum & VB2 & France & Sheep & Orchitis & {$[21]$} \\
\hline C. pecorum & W73 & Ireland & Sheep & Healthy (faeces) & [21] \\
\hline C. pneumoniae & CWL029 & USA & Human & Pneumonia & {$[62]$} \\
\hline C. trachomatis & A/HAR-13 & Saudi Arabia & Human & Conjunctivitis & {$[63]$} \\
\hline C. trachomatis & B/Jali20/OT & The Gambia & Human & Conjunctivitis & {$[62]$} \\
\hline C. trachomatis & B/TZ1A828/OT & Tanzania & Human & Conjunctivitis & [64] \\
\hline C. trachomatis & D/UW-3/CX & USA & Human & Genital tract infection & {$[65]$} \\
\hline C. trachomatis & L2/434/Bu & USA & Human & Bubo & {$[66]$} \\
\hline C. trachomatis & $\mathrm{L} 2 \mathrm{~b} / \mathrm{UCH}-1 /$ proctitis & England & Human & Proctitis & {$[66]$} \\
\hline
\end{tabular}

East Coomera population is located in South-East Queensland, approximately $54 \mathrm{~km}$ south of Brisbane and is comprised of approximately 500 koalas located in a 1716 ha area of cleared lands with isolated trees and small patches of native vegetation. The Brendale and Narangba populations are located among residential developments on the outskirts of Brisbane and are separated by a busy highway. The Pine Creek population is situated $20 \mathrm{~km}$ south of Coffs Harbour, New South Wales and consists of approximately 6400 ha of coastal eucalypt forest interspersed with pockets of rainforest, pasture and freehold incursions. The Pine Creek population was previously surveyed and was found to have $52 \%$ C. pecorum PCR positivity amongst animals screened [9].

A total of 295 ocular and urogenital swabs were collected from 80 koalas within the four populations. Ethics approval for the collection of swab samples from koalas was considered and provided by the QUT Animal
Research Ethics Committee (Approval number 0900000267).

For each sample, vials containing swabs and sucrose phosphate glutamate (SPG) transport media were vortexed for 30 seconds to release chlamydial bodies from the swab. $1 \mathrm{~mL}$ was transferred to a $1.5 \mathrm{~mL}$ eppendorf tube and centrifuged at $13,000 \times \mathrm{g}$ for 30 minutes to pellet the sample. Following removal of the supernatant, the pellet was resuspended in $50 \mu \mathrm{L}$ of SPG transport media and heated to $100^{\circ} \mathrm{C}$ for 2 minutes to release the DNA. Chlamydial DNA was then extracted using the tissue protocol of the QIAamp DNA kit (Qiagen).

\section{C. pecorum-specific diagnostic quantitative real-time PCR}

A total of 82 swabs from urogenital and ocular sites of the Narangba, Brendale, Pine Creek, and East Coomera koalas (65 animals) were screened for the presence of C. pecorum using a diagnostic quantitative real-time 
Table 2 Genomic region, primers, and melting temperatures for all genes investigated

\begin{tabular}{|c|c|c|c|c|c|c|}
\hline Gene & Annotation & \multicolumn{2}{|c|}{ Primer } & Sequence $\left(5^{\prime}-3^{\prime}\right)$ & $T_{a}$ & Size \\
\hline \multicolumn{7}{|c|}{ Housekeeping Genes } \\
\hline \multirow[t]{2}{*}{$16 \mathrm{~S}$ rRNA } & $16 S$ ribosomal subunit & & 16S-For & CTGAGAATTTGATCTTGG & $52^{\circ} \mathrm{C}$ & $1549 \mathrm{bp}$ \\
\hline & & & 16S-Rev & AAAGGAGGTGATCCAGC & & \\
\hline $16 \mathrm{~S} / 23 \mathrm{~S}$ & 16S-23S intergenic spacer & & Spacer-For & AAGGATAAGGAAAGCTATCA & $54^{\circ} \mathrm{C}$ & $225 \mathrm{bp}$ \\
\hline intergenic spacer & & & Spacer-Rev & AATTTTGATCCATGCAAGA & & \\
\hline \multicolumn{7}{|l|}{ Membrane Proteins } \\
\hline \multirow[t]{6}{*}{ ompA } & Outer membrane protein $\mathrm{A}$ & 1 & ompA-For & ATGAAAAAACTCTTAAAATCGG & $56^{\circ} \mathrm{C}$ & $1170 \mathrm{bp}$ \\
\hline & & & ompA-Rev & TTAGAATCTGCATTGAGCAG & & \\
\hline & & 2 & MJFvd3 $3^{a}$ & GGITG(CT)GCAACTITAGGIGC & $50^{\circ} \mathrm{C}$ & $457 \mathrm{bp}$ \\
\hline & & & MJRvd4 ${ }^{\mathrm{a}}$ & CACAAGCTTTTCTGGACTTC & & \\
\hline & & 3 & CpeNTVD $^{b}$ & GTTCTTTCTAACGTAGC & $46^{\circ} \mathrm{C}$ & 359 bp \\
\hline & & & CpeNTVD4 $^{\text {b }}$ & TGAAGAGAAACAATTTG & & \\
\hline \multirow[t]{2}{*}{ omcB } & Cysteine-rich outer & & omcB-For & ATGACCAAACTCATCAGAC & $54^{\circ} \mathrm{C}$ & $1675 \mathrm{bp}$ \\
\hline & membrane protein $B$ & & omcB-Rev & TTAATACACGTGGGTGTTTT & & \\
\hline \multirow[t]{2}{*}{$p m p D$} & Polymorphic membrane & & pmpD-For & ATGATCAGTCATATACGGAC & $56^{\circ} \mathrm{C}$ & $4145 \mathrm{bp}$ \\
\hline & protein D & & pmpD-Rev & TTAGAAAATCACGCGTACG & & \\
\hline \multirow[t]{2}{*}{ incA } & Inclusion membrane & & incA-S-F ${ }^{C}$ & TATCGTAATACCAAACCACT & $52^{\circ} \mathrm{C}$ & 984 bp \\
\hline & protein A & & incA-S-R & GTGTGAGATGGCTCTTTATG & & \\
\hline \multirow[t]{2}{*}{$\operatorname{copN}$} & Chlamydia outer protein $\mathrm{N}$ & & copN-For & ATGGCAGCTGGAGGGAC & $56^{\circ} \mathrm{C}$ & $1191 \mathrm{bp}$ \\
\hline & & & copN-Rev & TTATGACCAGGGATAAGGTT & & \\
\hline \multicolumn{7}{|c|}{ Potential Virulence Genes } \\
\hline \multirow[t]{4}{*}{$\operatorname{tar} P$} & Translocated actin-recruiting phosphoprotein & 1 & tarP-For & ATGACCTCTCCTATTAATGG & $56^{\circ} \mathrm{C}$ & $2604 \mathrm{bp}$ \\
\hline & & & tarP-Rev & CTAGTTAAAATTATCTAAGGTTT & & \\
\hline & & 2 & tarP-2-For & AAGAACCAACTCTGCATTATGAAGAGG & $54^{\circ} \mathrm{C}$ & 768 bp \\
\hline & & & tarP-2-Rev & AAGAGGTATTCACGCGACTTCCG & & \\
\hline \multirow[t]{2}{*}{ MACPF } & Membrane-attack & & MAC-For & TTGGCGATTCCTTTTGAAGC & $58^{\circ} \mathrm{C}$ & $2346 \mathrm{bp}$ \\
\hline & complex/perforin protein & & MAC-Rev & TTATAAGCACACACTAGGTCT & & \\
\hline \multirow[t]{2}{*}{ ORF663 } & Hypothetical protein & & $663-\mathrm{F}^{c}$ & AAACAACTGCACCGCTCTCT & $55^{\circ} \mathrm{C}$ & $1167 \mathrm{bp}$ \\
\hline & & & $663-R^{c}$ & GAAGGACTTTCTGGGGGAAG & & \\
\hline
\end{tabular}

'primers used for initial sequencing of full-length gene from MC/MarsBar/UGT type strain; ${ }^{2 / 3}$ primers used for second-stage sequencing from koala populations for further analysis; ${ }^{a}$ primers designed by [7]; ${ }^{b}$ primers designed by [10]; ${ }^{C}$ primers designed by [26].

PCR (RT-PCR) targeting a $204 \mathrm{bp}$ fragment of the $16 \mathrm{~S}$ rRNA gene.

The RT-PCR assay involved the addition of $3 \mu \mathrm{L}$ of chlamydial DNA to a PCR mixture containing $1 \times$ Faststart Taq DNA polymerase reaction buffer (Roche), $0.2 \mathrm{mM}$ deoxynucleotide triphosphates (Roche), $10 \mu \mathrm{M}$ primers (RT-Pec.sp-F: 5'-AGTCGAACGGAATAATGGCT-3', RTPec.sp-R: 5'-CCAACAAGCTGATATCCCAC-3'; Sigma), $0.25 \mathrm{U} / \mu \mathrm{L}$ Faststart Taq DNA polymerase (Roche), and $1 \mathrm{X}$ SensiMixPlus SYBR green (Quantace). All samples were assayed in triplicate. The MC/MarsBar type strain served as a positive control while $\mathrm{dH}_{2} \mathrm{O}$ was used as the negative control. PCR conditions were an initial denaturation of $94^{\circ} \mathrm{C}$ for 3 minutes, 40 cycles of denaturation at $94^{\circ} \mathrm{C}$ for 15 seconds, primer annealing at $57^{\circ} \mathrm{C}$ for 30 seconds, and DNA elongation at $72^{\circ} \mathrm{C}$ for 25 seconds. This was followed by a melting step from $70-90^{\circ} \mathrm{C}$. Equal numbers of C. pecorum positive samples $(\mathrm{n}=6)$ were randomly selected for further PCR amplification, sequencing, and analysis.

While incA and ORF663 were amplified and sequenced as full-length genes, smaller fragments of ompA and $\operatorname{tar} \mathrm{P}$ were used for analysis. These included a $465 \mathrm{bp}$ fragment of omp A that comprises the highly variable VD III and IV regions which were previously targeted in a range of phylogenetic and fine-detailed epidemiological studies $[11,21]$ and a 726 bp highly polymorphic fragment of the tarP gene.

\section{Phylogenetic analysis}

Phylogenetic reconstructions were performed under both distance and maximum-parsimony frameworks. Distance analyses were performed using the neighbour-joining algorithm and the Tamura-Nei model of molecular evolution as implemented in MEGA. Maximum parsimony analyses were conducted by using the tree-bisection and 
reconnection method of branch swapping and the heuristic search algorithm of PAUP* version 4.0b. Relative support for individual nodes was assessed by nonparametric bootstrapping, with 1000 replications of the data. The pairwise-deletion option was chosen to remove all sites containing missing data or alignment gaps from all distance estimations. Optimisation of the branch lengths was done by using the maximum-likelihood method (using Modeltest to define the evolutionary parameters [45]), subject to the constraint that all sampled sequences were contemporary (i.e., molecular clock was enforced). All rooted trees were constructed with mid-point rooting to facilitate genotypic comparisons of the outer topologies.

\section{Genotypic analysis}

The ability of each of the shortlisted genes to define specific genotypes within the koala populations was assessed, based on the nucleotide dissimilarity of sequences. To facilitate comparisons with previous research on koala $C$. pecorum infections, a similar genotyping approach was adopted where nucleotide dissimilarity $>1 \%$ (based on multiple sequence alignments of all koala strains for each gene) results in a new genotype $[7,8,46]$

\section{Recombination}

Recombination Detection Program (RDP) was used to test aligned sequences for recombination. This package utilises six published methods found to be sensitive for the identification of recombination and to yield the fewest false-positive findings [19]. The six methods are: RDP [47], GENECONV [48], Bootscan [49], MaxChi [50], Chimaera [51], and SiScan [52]. Different tests are applied to aligned sequences by each method to detect potentially recombinant regions [19]. The null hypothesis is clonality, i.e., that the pattern of sequence variation among the aligned sequences shows no indication of recombination [19]. Recombination was deemed to occur in a locus if clonality was rejected by three or more tests at a significance level of $P<0.001$ [19].

\section{GenBank accession numbers of novel sequences}

All novel $C$. pecorum sequences characterised in this study were submitted to GenBank and are available according to accession numbers HQ457440 to HQ457545.

\section{Results}

PCR amplification and sequence analysis of 10 candidate molecular markers from the koala $C$. pecorum type strain (MC/MarsBar)

Successful PCR amplification of each of the 10 gene loci was achieved using the primers and conditions outlined in Table 2. Analysis of the gene sequences for the selected targets is summarised in Table 3. The ompA, inc $\mathrm{A}, \operatorname{cop} \mathrm{N}$, and ORF663 gene sequences were analysed in conjunction with previously published $C$. pecorum data (Table 1), while the $16 \mathrm{~S}$ rRNA, 16S/23S intergenic spacer, $o m c \mathrm{~B}, p m p \mathrm{D}, \operatorname{tar} \mathrm{P}$, and $\mathrm{MACPF}$ genes were compared with the E58 reference strain as no other data is currently available for these genes.

In total, $16244 \mathrm{bp}$ of data was analysed which represents $1.62 \%$ of the complete $C$. pecorum genome. The two housekeeping and non-coding genes, 16S rRNA and $16 \mathrm{~S} / 23 \mathrm{~S}$ intergenic spacer, were sampled to provide a counterpoint to the coding sequence data and represent genes under stabilising selection. Across a total of 3548 bp of data from these two genes, only two SNPs were observed (0.13\%).

Analysis of ompA revealed a significantly higher level of polymorphisms (122), which equated to $10.43 \%$ of the $1170 \mathrm{bp}$ gene and a mean diversity of 0.162 . Both incA and ORF663, while possessing fewer individual polymorphisms than ompA (116 and 66 respectively), exhibited a higher percentage of nucleotide diversity at $11.79 \%$ and $11.96 \%$ respectively. This equated to a mean diversity of 0.656 for incA and 0.741 for ORF663. Together ompA, incA, and ORF663 were the most divergent genes out the 10 investigated. The remaining candidates were significantly more conserved with a five-fold reduction in nucleotide diversity. TarP exhibited 56 individual polymorphic sites out of 2604 bp (2.15\%) for an average diversity score of 0.029 , while MACPF was the most conserved of the coding genes investigated with only seven polymorphic sites $(0.30 \%)$, resulting in a mean diversity of 0.003 .

Within ompA, there were 72 mutations leading to a change in amino acid (non-synonymous mutations), representing $59.02 \%$ of the total nucleotide diversity for this locus. The $\mathrm{d} N / \mathrm{d} S$ ratio for $\operatorname{omp} \mathrm{A}$ was therefore 0.17 , which correlates with the D-value of 1.73 indicating ompA's considerable deviation from neutrality and tendency for negative selection. Interestingly, out of all eight coding genes investigated, omp A maintained the lowest percentage of non-synonymous mutations and therefore the lowest $\mathrm{d} N / \mathrm{d} S$ ratio. The $o m c \mathrm{~B}$ gene represented the opposite end of the scale with $87.5 \%$ of mutations leading to an amino acid replacement with a $\mathrm{d} N / \mathrm{d} S$ ratio of 2.15 .

The number of parsimony-informative sites and the discrimination index (D.I.) were calculated to enable each locus to be graded according to their discriminatory capacity, however, it is important to note that the estimates for both tests remain limited due to the mutual requirement for more than two sequences for analysis. Nevertheless, ompA had the most parsimonyinformative sites (111 sites), approximately twice as many as incA (59 sites). These results were slightly altered when considering the D.I. values as both inc A 
Table 3 Summary of nucleotide sequence variation between the MC/Mars Bar koala C. pecorum type strain and nonkoala $C$. pecorum strains in sampled regions of the $C$. pecorum genome

\begin{tabular}{|c|c|c|c|c|c|c|c|c|c|c|c|c|c|c|}
\hline Group and locus & $\mathrm{N}$ & Size (bp) & AlleleNo. & $\Delta \mathrm{nt}$ & $\%$ nt & $\pi$ & $\Delta$ rep & \%rep & $\Delta$ non-rep & $\%$ non-rep & $\mathrm{d} N / \mathrm{d} S$ & D & Pars & D.I. \\
\hline \multicolumn{15}{|l|}{ Housekeeping Genes } \\
\hline $16 \mathrm{~S}$ rRNA & 2 & 1549 & 2 & 2 & 0.130 & 0.001 & N/A & N/A & N/A & N/A & N/A & N/A & 0 & N/A \\
\hline 16S/23S intergenic spacer & 2 & 225 & 1 & 0 & 0.000 & 0 & N/A & N/A & N/A & N/A & N/A & N/A & 0 & N/A \\
\hline \multicolumn{15}{|l|}{ Membrane Proteins } \\
\hline ompA & 20 & 1170 & 13 & 122 & 10.430 & 0.162 & 72 & 59.020 & 21 & 17.210 & 0.170 & 1.734 & 111 & 0.910 \\
\hline omcB & 2 & 1675 & 2 & 8 & 0.420 & 0.004 & 7 & 87.500 & 1 & 12.500 & 2.150 & N/A & 0 & N/A \\
\hline pmpD & 2 & 4145 & 2 & 20 & 0.480 & 0.005 & 13 & 65.000 & 5 & 25.000 & 0.670 & N/A & 0 & $\mathrm{~N} / \mathrm{A}$ \\
\hline incA & 20 & 984 & 17 & 116 & 11.790 & 0.656 & 78 & 67.240 & 19 & 16.380 & 1.540 & 0.703 & 59 & 0.980 \\
\hline $\operatorname{copN}$ & 20 & 1191 & 9 & 9 & 0.760 & 0.008 & 9 & 55.560 & 5 & 44.440 & 0.550 & 1.163 & 7 & 0.880 \\
\hline \multicolumn{15}{|l|}{ Potential Virulence Genes } \\
\hline $\operatorname{tar} P$ & 2 & 2604 & 2 & 56 & 2.150 & 0.029 & 37 & 66.070 & 19 & 33.903 & 0.660 & $\mathrm{~N} / \mathrm{A}$ & 0 & N/A \\
\hline MACPF & 2 & 2346 & 2 & 7 & 0.300 & 0.003 & 5 & 71.430 & 2 & 28.570 & 0.730 & N/A & 0 & N/A \\
\hline ORF663 & 20 & 552 & 18 & 66 & 11.960 & 0.741 & 29 & 43.940 & 23 & 34.850 & 1.350 & 0.381 & 48 & 0.980 \\
\hline
\end{tabular}

$\mathrm{N}$ : no. of $C$. pecorum sequences analysed; Allele no.: no. of unique sequences according to gene; $\Delta$ nt: number of polymorphic nucleotide sites; \%nt: percent nucleotide sites polymorphic; $\pi$ : average $p$-distance at all sites; $\Delta$ rep: number of polymorphic sites resulting in an amino acid replacement; \%rep: percent sites with replacement; $\Delta$ non-rep: number of polymorphic sites not resulting in an amino acid replacement (synonymous changes); \%non-rep: percent sites with nonreplacement; $d N / d S$ : ratio of the number of non-synonymous $(d N)$ to synonymous $(d S)$ substitutions per site; D: Tajima's test for neutrality; Pars: parsimonyinformative sites; D.I.: discrimination index; D: Tajima's test for neutrality.

and ORF663 scored the highest (both 0.98), while ompA remained at 0.91 and $c o p N$ at 0.88 .

The ompA, incA, tarP, and ORF663 genes are potentially useful intra-species molecular markers of koala

\section{C. pecorum infections}

Based on the defined criteria for selecting fine-detailed molecular markers (see Materials and Methods), the $o m c \mathrm{~B}, p m p \mathrm{D}, \mathrm{MACPF}$, and $\operatorname{cop} \mathrm{N}$ genes had insufficient mean diversity and were not selected for further analysis. Conversely, the ompA, $\operatorname{tar} \mathrm{P}$, inc A, and ORF663 genes were able to satisfy this criterion and in addition, represent loci under diverse selection processes. Three of these four genes also offered useful D.I. values, while the unavailability of additional sequence data for tarP prevented its calculation. Nevertheless, tarP's adequate mean diversity and tendency for negative selection provided an important counterpoint to the highly divergent, positively-selected incA and ORF663 genes.

\section{Phylogenetic analysis of the ompA, inc $\mathrm{A}$, $\operatorname{tar} \mathrm{P}$, and ORF663 genes from clinical samples}

The phylogenetic analysis of our four targeted genes was prefaced with an evaluation of the mean genetic diversity for each locus based solely on the koala populations, in comparison with the data generated for non-koala hosts (Table 3). We observed a decreased level of mean diversity for ompA ( $p=0.096)$, ORF663 $(p=0.065)$, and incA $(p=0.016)$, which is anticipated given the expected contrast between the genetic variation present in our koala populations and the global samples of C. pecorum from multiple animal hosts. Interestingly, the $\operatorname{tar} \mathrm{P}$ gene produced a comparable figure of $p=0.028$. These results are significant from a global $C$. pecorum genetic diversity perspective, but this remains outside the scope of this study. In the context of the current study, this data importantly demonstrated that the incA value of $p=$ 0.016 for the koala populations is below the $p=0.02$ threshold required for intra-species differentiation.

Examination of the resulting phylogenetic trees revealed a level of resolution that was consistent with the corresponding gene's mean nucleotide diversity within the koala strains (Figure 1). Between each of the four trees there remained a consistent dissimilarity of branching orders, each with varying degrees of bootstrap support. Overall, there was a tendency for ompA and ORF663 to separate the Narangba and Brendale populations from the East Coomera and Pine Creek populations, while the tarP phylogenetic tree provided the most robust evidence for this distinction (Figure 1). The incA tree revealed less resolution between C. pecorum positive samples, correlating with its low level of mean sequence diversity and discriminatory power (Table 3 ).

To create a more comprehensive data set to permit more robust phylogenetic inferences, sequences for each of the four genes were concatenated and used in the construction of an additional phylogenetic tree (Figure 2). This tree produced largely similar groupings to those described above with the separation of the Narangba and Brendale populations from the Pine Creek and East Coomera populations, as well as the isolation of the more divergent $C$. pecorum positive samples from their respective populations. To test whether the phylogeny resulting from the concatenated sequence was biased by a single 


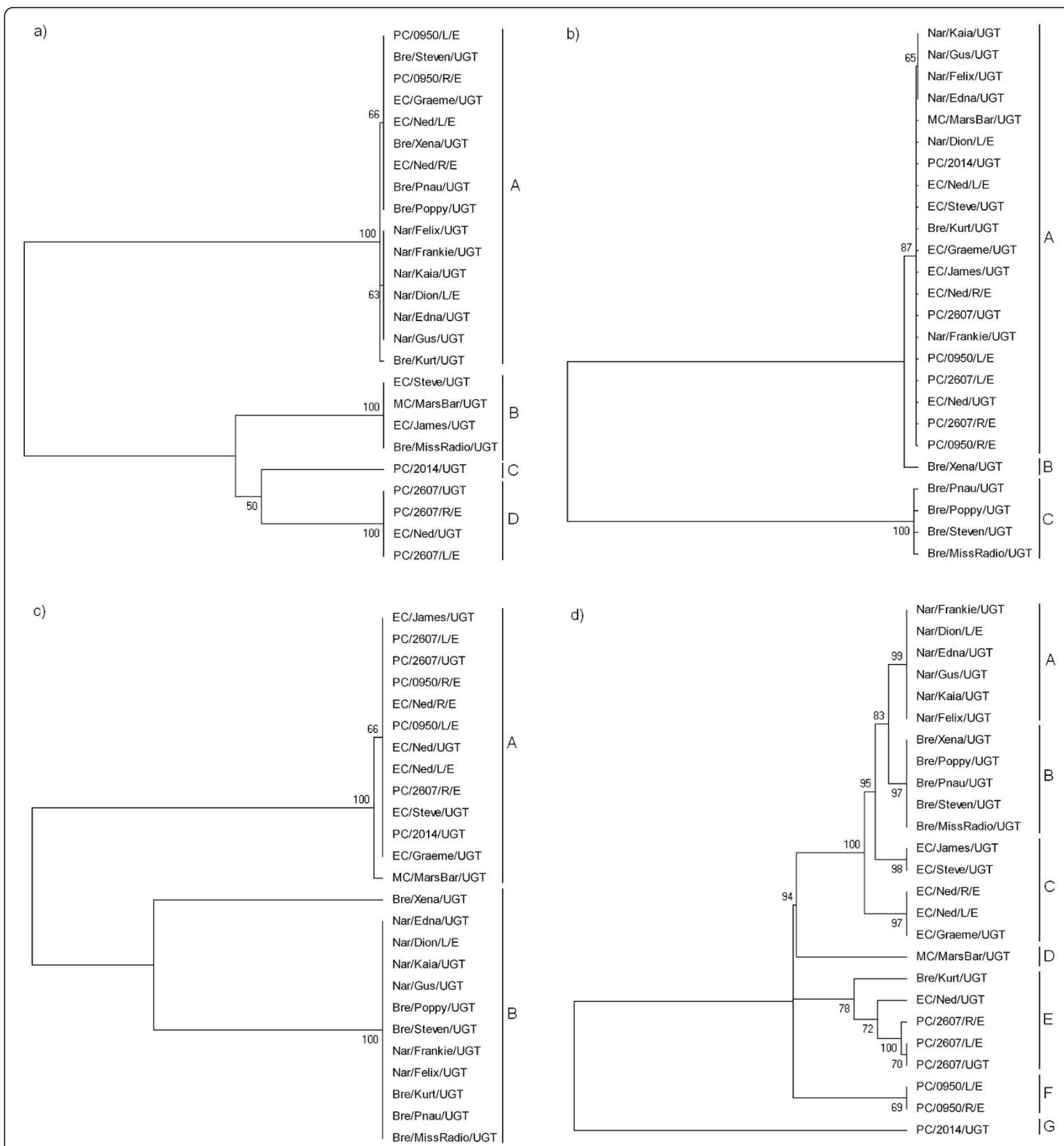

Figure 1 Mid-point rooted phylogenetic trees based on each of the four candidate genes. Inferred by the neighbour-joining method with bootstrapping support (1000 replicates). a) ompA; b) incA; c) tarP; d) ORF663.

locus, a subset of trees was built using the concatenated data with each region omitted. This resulted in no perturbation of the tree topology (data not shown).

In addition, a phylogenetic analysis was performed to examine the relationship between the koala C. pecorum samples analysed in this study, and other previously sequenced strains from non-koala hosts (Table 1).
Initially a tree was constructed using only $o m p \mathrm{~A}$ data (Figure 3) which clearly shows the koala C. pecorum sequences grouping with sheep and/or cattle strains rather than with each other. Subsequently, the sequence data for ompA, incA, and ORF663 were concatenated and a single phylogenetic tree constructed. While there was no visible relationship between geography or body 


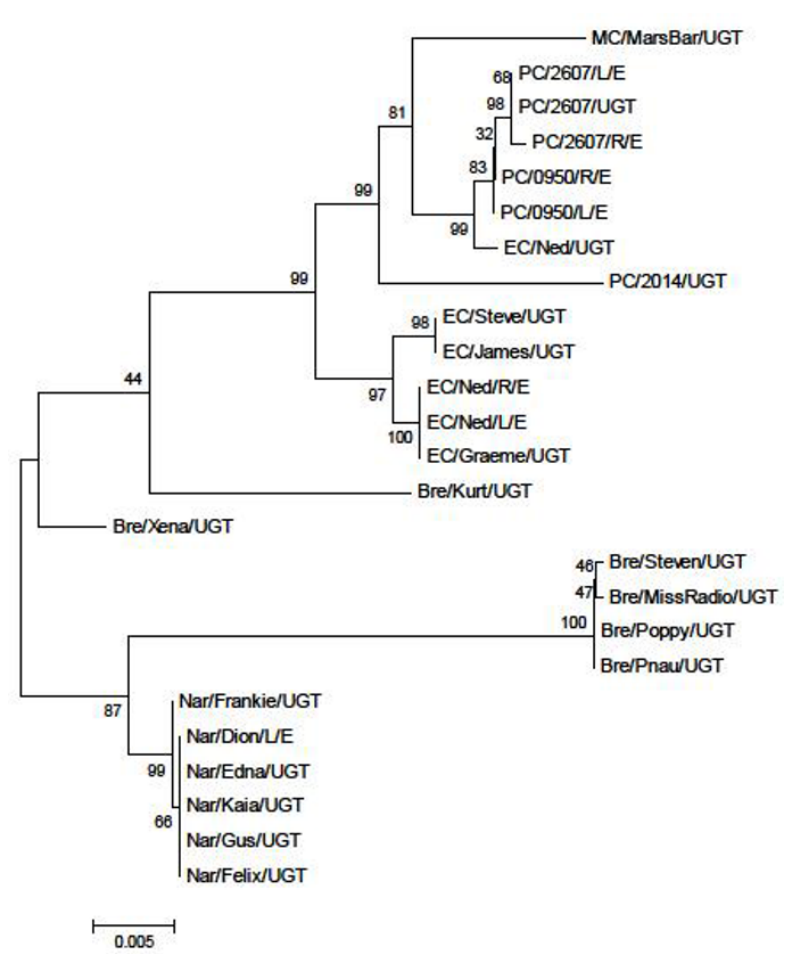

Figure 2 Phylogenetic tree from concatenated sequences of ompA, incA, ORF663, and tarP from all koala populations. Midpoint rooted and inferred by the neighbour-joining method with bootstrapping support (1000 replicates)

site of infection, there was a clear separation between the koala and non-koala strains (Figure 4). As ancestral relationships are not being inferred between the koala and non-koala hosts, unrooted phylogenetic trees were used to illustrate this data.

\section{Genotypic analysis of the ompA, incA, tarP, and ORF663 genes}

To highlight the discriminatory power of ompA, incA, tarP, and ORF663, C. pecorum-specific genotypes were established based on their level of nucleotide dissimilarity and aligned with the phylogenetic gene trees outlined above (Figure 1). The ompA gene was able to separate the koala samples into four genotypes, the incA gene produced three genotypes, the $\operatorname{tar} \mathrm{P}$ gene separated the clinical samples into two genotypes, while ORF663 was able to discriminate between seven distinct genotypes.

\section{Recombination}

Each of the four shortlisted genes (ompA, incA, ORF663, $\operatorname{tar} \mathrm{P})$ was tested for evidence of recombination by the RDP. All sequences were found to deviate from clonality by all six recombination tests $(P<0.001)$, which is consistent with previous reports regarding ompA and ORF663 [19,53].

\section{Discussion}

The current study revealed three novel and significant characteristics of the evolution and genetic diversity of C. pecorum infections in the koala: (1) the ompA gene has a phylogenetic history that is congruent with other gene targets in the $C$. pecorum genome, yet is phylogenetically-insufficient for use as a single gene marker; (2) the tarP and ORF663 genes are potentially useful in representing $C$. pecorum genomic diversity and evolution, and (3) koala C. pecorum infections appear to be monophyletic, possibly suggesting a limited number of cross-host transmission events between koalas and nonkoala hosts.

The ompA gene is one of the most polymorphic genes across all Chlamydia species [23] and as a result, was previously selected as the molecular marker of choice in epidemiological and genotyping studies of $C$. pecorum infections of the koala. This increased nucleotide diversity is reported to be due to the antigenicity of MOMP and the selective pressure of the host's immune response [54]. Early C. trachomatis studies and more recent C. pecorum studies suggested that the phylogenetic categorisation of the ompA gene is not concordant with pathobiotypes, tissue tropisms, or the evolution of the genome as a whole $[7,11,18,20,21]$. Based on these findings, the use of ompA gene as a molecular marker of koala $C$. pecorum genetic diversity also required re-evaluation.

Assumptions on the validity of ompA as a genetic marker for koala $C$. pecorum strains must be preceded by an appreciation of the koala $C$. pecorum phylogeny. Without in-depth MLST studies to determine the true C. pecorum phylogeny, this study applied our four genes of interest (ompA, incA, ORF663 and tarp), to a multilocus approach to phylogeny in an effort to recreate the most accurate phylogenetic signal (Figure 2) using single gene targets. Some level of phylogenetic discordance is expected between these genes given their diverse metabolic function, chromosomal location, possibility for evolutionary rate heterogeneity and the susceptibility of all four genes to recombination events. However, this multi-locus method benefits from a "majority rule" approach by allowing the amplification of congruous phylogenetic information while reducing the effects of phylogenetic "noise". In addition, the equalisation of outer branch lengths serves to resolve minor phylogenetic inconsistencies. Together, this results in a more accurate phylogeny than that inferred from a single gene $[55,56]$. There was no perturbation of the tree topology when each gene was sequentially omitted from analysis, alleviating concerns that individual genes may dominate and sweep the phylogenetic signal. It is expected that the systematic addition of further gene data will continue to produce a more refined and resolute phylogeny, 


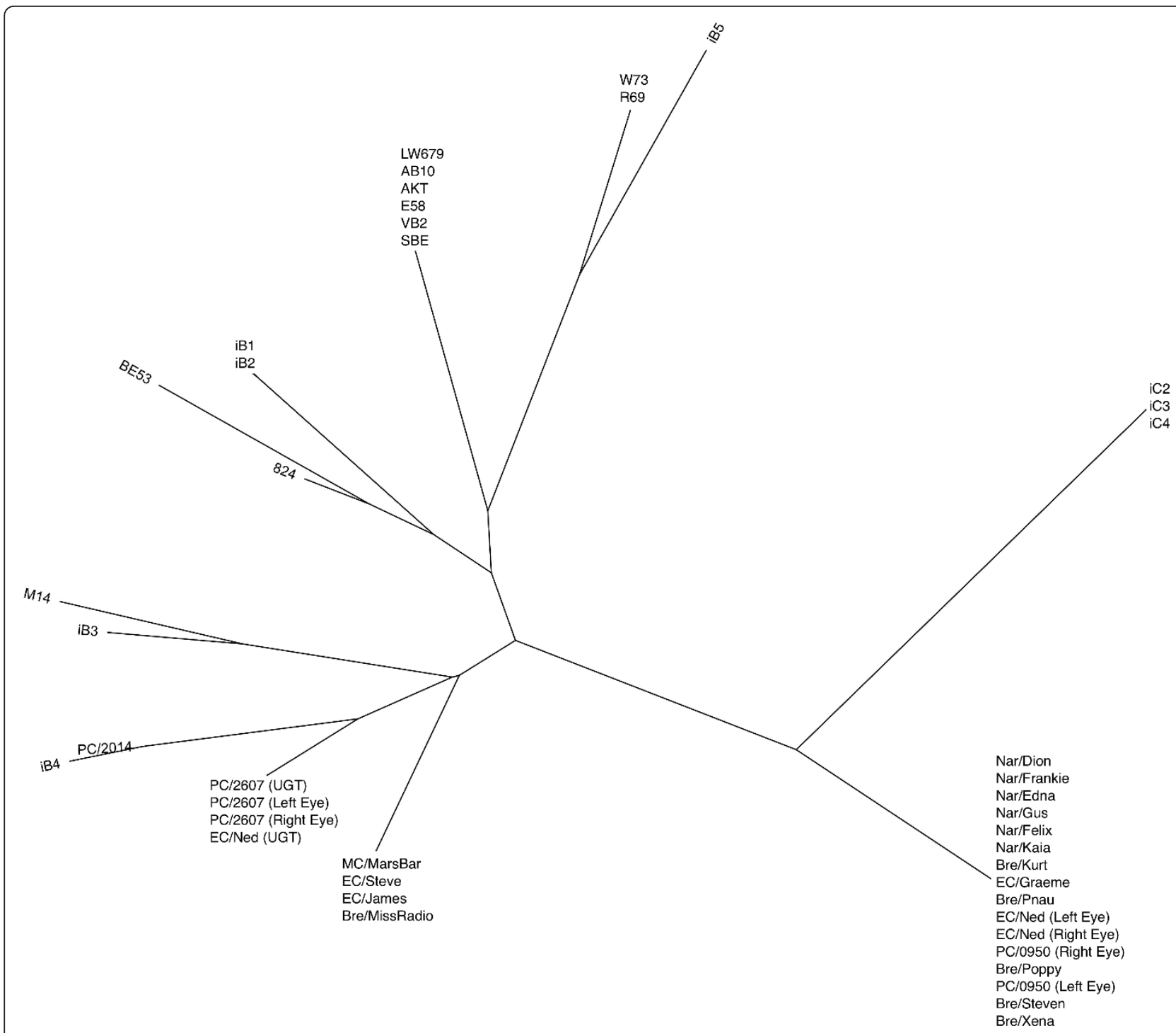

Figure 3 Phylogenetic tree of ompA sequences from koala $C$. pecorum isolates, with previously published sequence information. Unrooted; inferred by the neighbour-joining method with bootstrapping support (1000 replicates).

however we suggest that the phylogenetic tree using concatenated sequences of ompA, incA, ORF663, and tar $\mathrm{P}$ provides a preliminary and useful indication of the true phylogenetic relationship between these koala C. pecorum samples and a prelude to future MLST and phylogenetic studies.

The phylogenetic tree generated from concatenated data clearly defines two distinct lineages between the four populations investigated: (1) the Pine Creek and East Coomera populations (separated by $\sim 500 \mathrm{kms}$ ), and (2) the Narangba and Brendale populations (separated by $\sim 5 \mathrm{kms}$ ), while each lineage is further subdivided into two clades, each representing an individual population. From an evolutionary standpoint, this phylogenetic reconstruction appears valid. For example, it is clear that the Brendale and Narangba populations remain geographically (and genetically) similar, as do the East Coomera and Pine Creek populations, albeit to a lesser degree. The genetic diversity and uniqueness of geographically isolated C. pecorum strains is presumably the result of disturbances to koala population distribution and structure from land clearing and urban pressure over the last 200 years of European settlement, leading to the formation of isolated koala colonies in which C. pecorum strains continue to undergo local selection and adaptation. The question that remains is how effective are the four shortlisted genes in abbreviating this vast phylogenetic information for epidemiological study?

Beginning with ompA, previous C. pecorum studies suggest that this gene is reflective of the overall evolution 


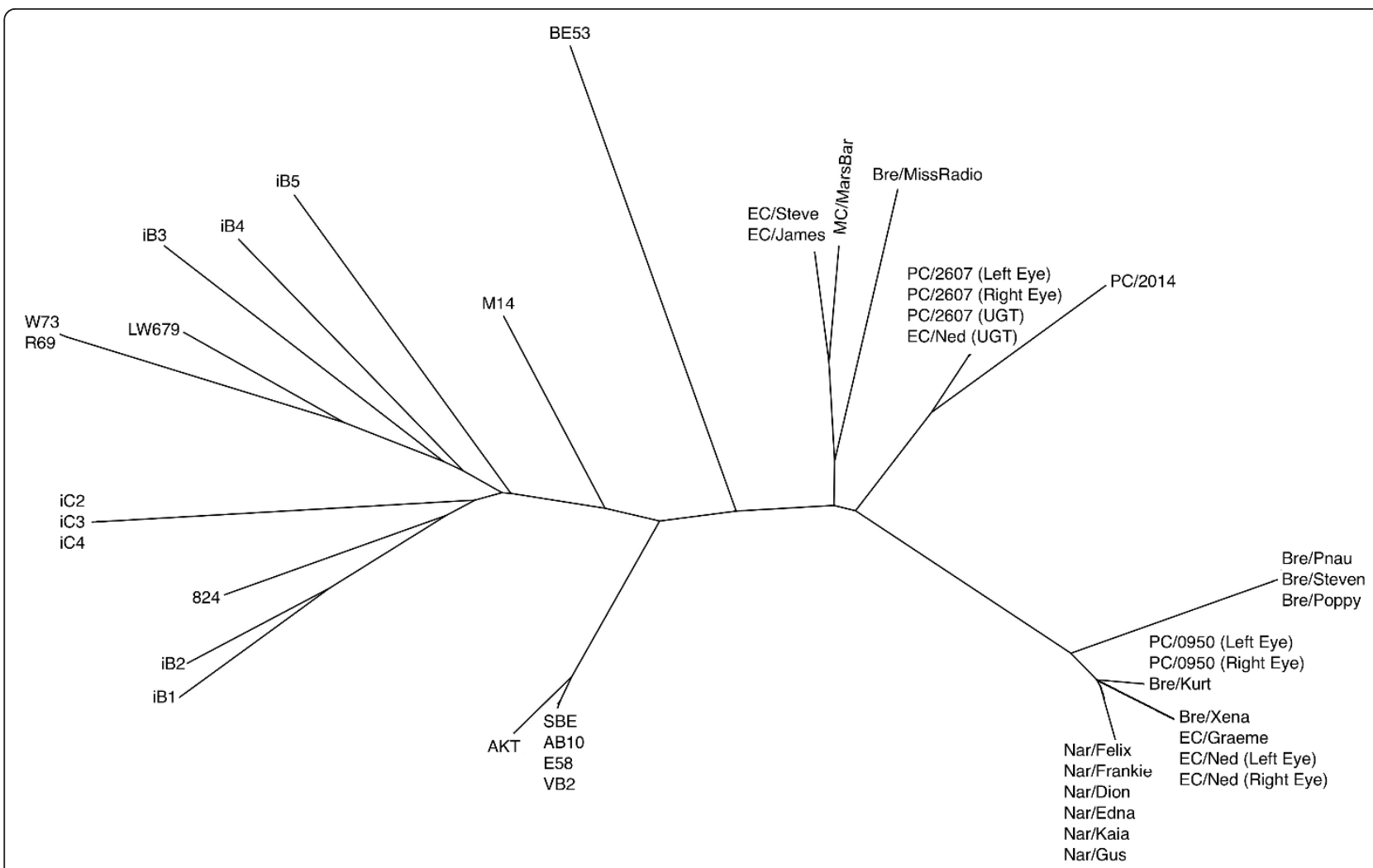

Figure 4 Phylogenetic tree of the koala C. pecorum isolates sequenced, with previously published sequence information. Unrooted; constructed using concatenated sequences of ompA, incA, and ORF663 using the neighbour-joining method with bootstrapping support (1000 replicates).

of the C. pecorum genome [7,23], however these studies are based on broad comparisons between chlamydial species and do not represent evolutionary lineages on an intra-species level. Alternatively, intra-species C. trachomatis studies have indicated that the ompA locus differs from other regions of its genome [19]. The results of the present study illustrate a tendency for the phylogenetic topology of the ompA gene to separate the Narangba/Brendale populations from the Pine Creek/East Coomera populations while other, more divergent strains do not cluster according to their respective population. This data would appear to correlate with previous C. pecorum fine-detailed epidemiological studies where it was concluded, using the ompA gene, that an association between the site of koala capture and the genotype of its resident $C$. pecorum strain usually exists, while some genotypes were distributed widely into different geographic areas [7]. The phylogenetic divisions offered by the tree using concatenated sequences, however, clearly show that regions of the ompA gene are actively contributing to a misinterpretation of the "true" phylogenetic signal. This observation supports previous conclusions that ompA is ineffective as a genome-representative marker. It is therefore suggested that while the ompA gene continues to be a useful fine-detailed comparative marker, it remains suboptimal for any phylogenetic, evolutionary and/or biogeographic analysis. Both the $\operatorname{tar} \mathrm{P}$ and ORF663 genes, conversely, are appealing alternatives to ompA.

The $\operatorname{tar} \mathrm{P}$ gene encodes the translocated actin-recruiting phosphoprotein [57] which has important virulent functions involved in the attachment of the chlamydial elementary body to the host cell [28]. The tarP gene's tendency for negative selection and relatively low mean nucleotide diversity reinforces its important biological role in the chlamydial cell and typifies a gene that changes slowly enough to make it useful as an evolutionary chronometer [41]. Recent $C$. trachomatis studies have suggested that the full-length $\operatorname{tar} P$ gene, based on the inverse relationship between the number of tyrosine repeats and the number of actin-binding domains, can be correlated with clinical phenotype [58], highlighting its potential as a useful genetic marker.

The koala C. pecorum tarP gene phylogenetic tree produced two distinct clades which, interestingly, revealed a clear separation between the Brendale and Narangba isolates and the Pine Creek and East Coomera isolates. Initially, there appeared to be no distinction between ocular 
and urogenital sites of infection, however upon further inspection, it was clear that (with the exception of Nar/ Dion (Left Eye)), all the ocular isolates remained confined to one phylogenetic clade (among seven urogenital isolates) which are distinct from the remaining urogenital isolates. Importantly, this ocular "outlier" (Nar/Dion (Left Eye)) retains $100 \%$ nucleotide similarity with the remaining isolates within the Narangba population, all of which were isolated from urogenital sites of infection. Coupled with the fact that isolate 'Ned' from the East Coomera population harbours genetically distinct ocular and urogenital isolates of $C$. pecorum, this suggests that high rates of transmission within these confined koala populations may contribute to the transfer of C. pecorum from one body site to another and that the site of detection may not be the original niche of the strain [58]. It appears that the tarP gene has potential as a phenotypic-dependent marker, however, importantly, further investigation is required that utilises the full-length tarP gene (in conjunction with wider geographic sampling) to properly determine its true potential.

From a full genome evolutionary standpoint, the separation of the Brendale/Narangba populations from the Pine Creek/East Coomera populations is a distinction that is clearly mirrored in the overall phylogenetic analysis using concatenated data. This suggests that $\operatorname{tar} \mathrm{P}$, although having a relatively low rate of substitution, is capable of more accurately and specifically differentiating koala strains according to geography than ompA and ORF663, albeit with reduced resolution. For these reasons, $\operatorname{tar} \mathrm{P}$ also appears promising as an evolutionary indicator and may be classified as a "neutral marker", characterised by its selective constraints yet ability to reflect sequence diversity between koala populations that are geographically separate [59]. However, as a "neutral marker", the $\operatorname{tar} \mathrm{P}$ gene remains less useful when estimating a population's adaptive potential or local population divergence.

ORF663 encodes a hypothetical protein and includes a 15 nucleotide variant coding tandem repeat (CTR) region that putatively associates it with a virulence-related role. Interestingly, this gene has not been identified in any other chlamydial species and BLAST search reveals no similarities to any other sequences in the database. The C. pecorum ORF663 gene was the most polymorphic gene among all investigated and represents a locus under considerable positive selection. Using this gene, we were able to observe the most distinctions between strains by identifying seven separate genotypes. These genotypes highlight the considerable discriminatory capacity of ORF663 which correlates with (while extending) the divisions made by ompA and tarP, by isolating the Narangba and Brendale populations into their own genotypes while separating the more heterogeneous Pine Creek and East
Coomera populations into multiple genotypes. Where the $\operatorname{tar} \mathrm{P}$ gene represents a neutral marker that assumes isolates within a population are equally related to each other, ORF663 can be considered a "divergence-based" or "contingency" marker that is capable of characterising diversity both within and between populations for finedetailed epidemiological study.

The value of the marker genes identified in this study was extended to consider the genetic diversity between C. pecorum infections in koalas and non-koala hosts. Previous research has suggested that, supported by ompA VD3/4 sequence data, C. pecorum is a polyphyletic organism in Australian koala populations. This hypothesis originated from the similarity of one or two koala omp A genotypes to European bovine isolates of C. pecorum $[7,11]$ and based on this data, a model was proposed whereby koalas obtained C. pecorum infections as a result of a series of cross-species transmission events from sheep and/or cattle $[7,8,11,60]$. While similar results were obtained using ompA data in this study (Figure 3), the phylogenetic analysis has already suggested in inadequacy of the ompA gene alone in representing C. pecorum's true evolutionary course within koala populations. Indeed, both this and previous studies utilised a $465 \mathrm{bp}$ fragment of the ompA locus (VD 3/4) which, while containing the majority of ompA's nucleotide variation, would remain largely insufficient to describe the extensive genetic diversity that has accumulated in global isolates of C. pecorum.

Consequently, we prepared an unrooted phylogenetic tree from the concatenation of incA, ompA, and ORF663 sequences, revealing a surprising alternative picture that clearly distinguishes koala C. pecorum strains from nonkoala hosts (Figure 4). This distinction is further supported by the noticeable difference in branch lengths between koala C. pecorum sequences and non-koala hosts, suggesting that as a whole, koala strains are much more closely related to each other than to other nonkoala host strains. This result is significant as it may be an example of an alternate evolutionary model in which koalas obtained C. pecorum as a result of a limited number of cross-host transmission events in the past and have subsequently evolved along an evolutionary trajectory that is distinct from that seen in sheep and cattle isolates. This result also reinforces the benefit and efficacy of applying more phylogenetically-robust data (the concatenation of three congruent genes) to the epidemiological study of C. pecorum infections, both in koala and non-koala hosts. It must be noted however, that this remains a cautionary finding. Without $o m p \mathrm{~A}$, inc A, and ORF663 nucleotide sequences from Australian sheep and cattle isolates it remains impossible to truly establish a compelling cross-host transmission hypothesis for koala isolates. Nevertheless, this data cannot be completely 
discounted and functions as preliminary insight into the genetic diversity of koala isolates of C. pecorum.

\section{Conclusions}

The findings of this study have highlighted the opportunities and drawbacks of estimating phylogenetic relationships from multiple independent datasets [61]. A concatenation approach to phylogenetic inference appears promising, however a true evolutionary reconstruction of the C. pecorum lineage may require a rigorous MLST approach that incorporates genetic data from several more independent loci and extensive geographic sampling.

It is clear that the ompA gene is distorted by technical and biological interference rendering it incapable of representing true phylogenetic divisions as a molecular marker, yet it remains useful as a fine-detailed, cost-effective, comparative marker for fine-detailed epidemiological investigation of large numbers of koala C. pecorum positive samples. Alternatively, the $\operatorname{tar} \mathrm{P}$ gene's ability as a "neutral marker" to provide a "bird's-eye-view" on higher levels of evolutionary divergence between koala populations and ORF663's opportunities as a contingency marker are promising for future phylogenetic studies in the koala.

While three out of our four shortlisted genes (including omp A) proved to be effective gene markers, incA was ultimately deemed to be the least effective and was discarded from further analysis. However, the significant discrepancy noted between the mean diversity of incA from koala and non-koala hosts (as well as ORF663) invites intriguing questions regarding the genetic diversity of C. pecorum beyond the koala host which, while outside the scope of this study, will be important in subsequent research in this area.

Although this study focussed on a mere 10 genes in the C. pecorum genome, it successfully challenged ompA as a molecular marker and provided an important opportunity to review previous knowledge on the genetic diversity of C. pecorum in Australian koala populations. The availability of the complete E58 C. pecorum genome sequence and, eventually, a koala C. pecorum genome, will facilitate the characterisation of additional genes and promote further analyses of genomic variation to support comprehensive surveys of lineage prevalence within and between koala populations. Until then, the data described here provides a solid foundation for this subsequent research by highlighting a robust measurement tool for koala C. pecorum infections and presents a compelling depiction of their phylogenetic relationships. This application will have importance for our ability to successfully map, control and manage diseased populations of this dwindling native icon.

\section{Acknowledgements}

The authors would like to acknowledge the generosity of Gary Myers, Institute for Genome Sciences, University of Maryland, Baltimore, USA for allowing us access to the C. pecorum E58 genome sequence. We would also like to acknowledge Jon Hanger and Jo Loader (Australian Wildlife Hospital, Beerwah, Australia), Jon Callaghan (Gold Coast City Council, Gold Coast, Australia) and Jeff McKee (Ecosure, Gold Coast, Australia) for their valuable contribution to the collection of koala swabs from Brendale, Narangba, East Coomera and Pine Creek koala populations, respectively. This study was financially supported by ARC Linkage scheme grant (LP0990147) "Development of an anti-Chlamydia vaccine in the koala" awarded to PT.

\section{Authors' contributions}

JM carried out the laboratory work, performed all sequence, phylogenetic and statistical analyses, and drafted the manuscript. AK performed the processing of koala swabs, PCR screening and ompA sequencing of $C$. pecorum-positive samples. PT and AP conceived the study, participated in its design and coordination and assisted in drafting the manuscript. All authors read and approved the final manuscript.

Received: 4 November 2010 Accepted: 18 April 2011

Published: 18 April 2011

\section{References}

1. Moulder J: Interaction of chlamydiae and host cells in vitro. Microbiol Mol Biol Rev 1991, 55(1):143.

2. Everett KDE, Bush RM, Andersen AA: Emended description of the order Chlamydiales, proposal of Parachlamydiaceae fam. nov. and Simkaniaceae fam. nov., each containing one monotypic genus, revised taxonomy of the family Chlamydiaceae, including a new genus and five new species, and standards for the identification of organisms. Int J Syst Evol Microbiol 1999, 49(2):415-440.

3. Stephens RS, Myers G, Eppinger M, Bavoil PM: Divergence without difference: Phylogenetics and taxonomy of Chlamydia resolved. FEMS Immunol Med Microbiol 2009, 55(2):115-119.

4. Greub G: International Committee on Systematics of Prokaryotes. Subcommittee on the taxonomy of the Chlamydiae: Minutes of the inaugural closed meeting, 21 March 2009, Little Rock, AR, USA. Int J Syst Evol Microbiol 2010, 60:2691-2693.

5. Greub G: International Committee on Systematics of Prokaryotes. Subcommittee on the taxonomy of the Chlamydiae: Minutes of the closed meeting, 21 June 2010, Hof bei Salzburg, Austria. Int J Syst Evol Microbiol 2010, 60:2694.

6. Cockram FA, Jackson AR: Keratoconjunctivitis of the koala, Phascolarctos cinereus, caused by Chlamydia psittaci. J Wildl Dis 1981, 17(4):497-504.

7. Jackson M, Giffard P, Timms P: Outer membrane protein A gene sequencing demonstrates the polyphyletic nature of koala Chlamydia pecorum isolates. Syst Appl Microbiol 1997, 20(2):187-200.

8. Jackson M, White N, Giffard P, Timms P: Epizootiology of Chlamydia infections in two free-range koala populations. Vet Microbiol 1999, 65(4):255-264.

9. Devereaux LN, Polkinghorne A, Meijer A, Timms P: Molecular evidence for novel chlamydial infections in the koala (Phascolarctos cinereus). Syst Appl Microbiol 2003, 26(2):245-253.

10. Wardrop S, Fowler A, O'Callaghan P, Giffard P, Timms P: Characterisation of the koala biovar of Chlamydia pneumoniae at four gene loci - ompAVD4, ompB, 16S rRNA, groESL spacer region. Syst Appl Microbiol 1999, 22(1):22-27.

11. Kaltenboeck B, Heinen E, Schneider R, Wittenbrink MM, Schmeer N: OmpA and antigenic diversity of bovine Chlamydophila pecorum strains. Vet Microbiol 2009, 135(1-2):175-180.

12. Brown AS, Grice RG: Isolation of Chlamydia psittaci from koalas (Phascolarctos cinereus). Aust Vet J 1984, 61(12):413.

13. Brown AS, Girjes AA, Lavin MF, Timms P, Woolcock JB: Chlamydial disease in koalas. Aust Vet J 1987, 64(11):346-350.

14. Girjes AA, Hugall AF, Timms P, Lavin MF: Two distinct forms of Chlamydia psittaci associated with disease and infertility in Phascolarctos cinereus (koala). Infect Immun 1988, 56(8):1897-1900.

15. Zhang YX, Fox JG, Ho Y, Zhang L, Stills HF Jr, Smith TF: Comparison of the major outer-membrane protein (MOMP) gene of mouse pneumonitis 
(MoPn) and hamster SFPD strains of Chlamydia trachomatis with other Chlamydia strains. Mol Biol Evol 1993, 10(6):1327-1342.

16. Girjes AA, Hugall A, Graham DM, McCaul TF, Lavin MF: Comparison of Type I and Type II Chlamydia psittaci strains infecting koalas (Phascolarctos cinereus). Vet Microbiol 1993, 37(1-2):65-83.

17. Girjes AA, Weigler BJ, Hugall AF, Carrick FN, Lavin MF: Detection of Chlamydia psittaci in free-ranging koalas (Phascolarctos cinereus): DNA hybridization and immuno-slot blot analyses. Vet Microbiol 1989, 21(1):21-30.

18. Fitch WM, Peterson EM, De la Maza LM: Phylogenetic analysis of the Outer Membrane Protein genes of Chlamydiae, and its implication for vaccine development. Mol Biol Evol 1993, 10(4):892-913.

19. Brunelle B, Sensabaugh $G$ : The ompA gene in Chlamydia trachomatis differs in phylogeny and rate of evolution from other regions of the genome. Infect Immun 2006, 74(1):578.

20. Pannekoek Y, Morelli G, Kusecek B, Morré S, Ossewaarde J, Langerak A, Van Der Ende A: Multi locus sequence typing of Chlamydiales: clonal groupings within the obligate intracellular bacteria Chlamydia trachomatis. BMC Microbiol 2008, 8(1):42.

21. Yousef Mohamad K, Roche SM, Myers G, Bavoil PM, Laroucau K, Magnino S, Laurent S, Rasschaert D, Rodolakis A: Preliminary phylogenetic identification of virulent Chlamydophila pecorum strains. Infect, Genet Evol 2008, 8(6):764-771.

22. Everett $K D$, Andersen $A A$ : The ribosomal intergenic spacer and domain I of the $23 \mathrm{~S}$ rRNA gene are phylogenetic markers for Chlamydia spp. Int J Syst Evol Microbiol 1997, 47(2):461-473.

23. Kaltenboeck B, Kousoulas KG, Storz J: Structures of and allelic diversity and relationships among the major outer membrane protein (ompA) genes of the four chlamydial species. J Bacteriol 1993, 175(2):487-502.

24. Fadel S, Eley A: Chlamydia trachomatis omcB protein is a surface-exposed glycosaminoglycan-dependent adhesin. J Med Microbio/ 2007, 56(1):15.

25. Grimwood J, Stephens RS: Computational analysis of the polymorphic membrane protein superfamily of Chlamydia trachomatis and Chlamydia pneumoniae. Microb Comp Genomics 1999, 4(3):187-201.

26. Yousef Mohamad K, Rekiki A, Myers G, Bavoil P, Rodolakis A: Identification and characterisation of coding tandem repeat variants in incA gene of Chlamydophila pecorum. Vet Res 2008, 39(6):56-56.

27. Hsia R, Pannekoek Y, Ingerowski E, Bavoil P: Type III secretion genes identify a putative virulence locus of Chlamydia. Mol Microbiol 1997 25(2):351-359.

28. Jewett TJ, Fischer ER, Mead DJ, Hackstadt T: Chlamydial Tarp is a bacterial nucleator of actin. Proc Natl Acad Sci USA 2006, 103(42):15599.

29. Ponting C: Chlamydial homologues of the MACPF (MAC/perforin) domain. Curr Biol 1999, 9(24):1-30.

30. Sanger $F$, Nicklen $S$, Coulson A: DNA sequencing with chain-terminating inhibitors. Proc Natl Acad Sci USA 1977, 74(12):5463.

31. Thompson JD, Higgins DG, Gibson TJ: CLUSTAL W: Improving the sensitivity of progressive multiple sequence alignment through sequence weighting, position-specific gap penalties and weight matrix choice. Nucleic Acids Res 1994, 22(22):4673-4680

32. Wernersson R, Pedersen A: RevTrans: Multiple alignment of coding DNA from aligned amino acid sequences. Nucleic Acids Res 2003, 31(13):3537.

33. Librado P, Rozas J: DnaSP v5: A software for comprehensive analysis of DNA polymorphism data. Bioinformatics 2009, 25(11):1451.

34. Kumar S, Nei M, Dudley J, Tamura K: MEGA: A biologist-centric software for evolutionary analysis of DNA and protein sequences. Brief Bioinform 2008, 9(4):299-306.

35. Nei $M$, Gojobori T: Simple methods for estimating the numbers of synonymous and nonsynonymous nucleotide substitutions. Mol Biol Evol 1986, 3(5):418.

36. Simpson E: Measurement of diversity. Nature 1949, 163(4148):688

37. Gomes J, Nunes A, Bruno W, Borrego M, Florindo C, Dean D: Polymorphisms in the nine polymorphic membrane proteins of Chlamydia trachomatis across all serovars: Evidence for serovar Da recombination and correlation with tissue tropism. J Bacteriol 2006, 188(1):275.

38. Nunes A, Nogueira P, Borrego M, Gomes J: Chlamydia trachomatis diversity viewed as a tissue-specific coevolutionary arms race. Genome Biol 2008, 9(10):110-123.

39. Greub G, Collyn F, Guy L, Roten C: A genomic island present along the bacterial chromosome of the Parachlamydiaceae UWE 25, an obligate amoebal endosymbiont, encodes a potentially functional F-like conjugative DNA transfer system. BMC Microbiol 2004, 4(1):48.

40. Eugster M, Roten C, Greub G: Analyses of six homologous proteins of Protochlamydia amoebophila UWE 25 encoded by large GC-rich genes: A model of evolution and concatenation of leucine-rich repeats. BMC Evol Biol 2007, 7(1):231.

41. Woese CR: Bacterial evolution. Microbiol Mol Biol Rev 1987, 51(2):221-271.

42. Watve $M$, Gangal R: Problems in measuring bacterial diversity and a possible solution. Appl Environ Microbiol 1996, 62(11):4299.

43. Mills A, Wassel R: Aspects of diversity measurement for microbial communities. Appl Environ Microbiol 1980, 40(3):578.

44. Ikryannikova LN, Shkarupeta MM, Shitikov EA, Ilina EN, Govorun VM: Comparative evaluation of new typing schemes for urogenital Chlamydia trachomatis isolates. FEMS Immunol Med Microbiol 2010, 6(2):144-156.

45. Posada D, Crandall KA: Modeltest: Testing the model of DNA substitution. Bioinformatics 1998, 14(9):817.

46. Timms P, Eaves FW, Girjes AA, Lavin MF: Comparison of Chlamydia psittaci isolates by restriction endonuclease and DNA probe analyses. Infect Immun 1988, 56(1):287-290.

47. Martin D: Recombination detection and analysis using RDP3. Methods Mol Biol 2009, 537:185-205.

48. Padidam M, Sawyer S, Fauquet C: Possible emergence of new geminiviruses by frequent recombination. Virology 1999, 265(2):218-225.

49. Salminen M, Carr J, Burke D, McCutchan F: Identification of breakpoints in intergenotypic recombinants of HIV type 1 by bootscanning. AIDS Res Hum Retroviruses 1995, 11(11):1423.

50. Smith J: Analyzing the mosaic structure of genes. J Mol Evol 1992, 34(2):126-129.

51. Posada D, Crandall K: Evaluation of methods for detecting recombination from DNA sequences: Computer simulations. Proc Natl Acad Sci USA 2001, 98(24):13757.

52. Gibbs M, Armstrong J, Gibbs A: Sister-scanning: A Monte Carlo procedure for assessing signals in recombinant sequences. Bioinformatics 2000, 16(7):573.

53. Yousef Mohamad K, Rodolakis A: Recent advances in the understanding of Chlamydophila pecorum infections, sixteen years after it was named as the fourth species of the Chlamydiaceae family. Vet Res 2010, 41(27):199-209.

54. Stephens RS, Sanchez-Pescador R, Wagar EA, Inouye C, Urdea MS: Diversity of Chlamydia trachomatis major outer membrane protein genes. $J$ Bacteriol 1987, 169(9):3879-3885.

55. Pamilo P, Nei M: Relationships between gene trees and species trees. Mol Biol Evol 1988, 5(5):568.

56. Degnan J, Rosenberg N: Gene tree discordance, phylogenetic inference and the multispecies coalescent. Trends Ecol Evol 2009, 24(6):332-340.

57. Wang J, Chen L, Chen F, Zhang X, Zhang Y, Baseman J, Perdue S, Yeh IT, Shain R, Holland M: A chlamydial type III-secreted effector protein (Tarp) is predominantly recognized by antibodies from humans infected with Chlamydia trachomatis and induces protective immunity against upper genital tract pathologies in mice. Vaccine 2009, 27(22):2967-2980.

58. Lutter E, Bonner C, Holland M, Suchland R, Stamm W, Jewett T, McClarty G, Hackstadt T: Phylogenetic analysis of Chlamydia trachomatis tarP and correlation with clinical phenotype. Infect Immun 2010, 78(9):3678,

59. Leinonen T, O'hara R, Cano J, Merila J: Comparative studies of quantitative trait and neutral marker divergence: A meta-analysis. J Evol Biol 2008, 21(1):1-17.

60. Timms P: Chlamydial infection and disease in the koala. Microbiol Aus 2005, 26(2):65-68.

61. Moyer $G$, Remington $R$, Turner $T$ : Incongruent gene trees, complex evolutionary processes, and the phylogeny of a group of North American minnows. Mol Phylogen Evol 2009, 50(3):514-525.

62. Kalman S, Mitchell W, Marathe R, Lammel C, Fan J, Hyman RW: Comparative genomes of Chlamydia pneumoniae and C. trachomatis. Nat Genet 1998, 21(4):385-389.

63. Carlson JH, Porcella SF, McClarty G, Caldwell HD: Comparative genomic analysis of Chlamydia trachomatis oculotropic and genitotropic strains. Infect Immun 2005, 73(10):6407-6418.

64. Seth-Smith HMB, Harris SR, Persson K, Marsh P, Barron A, Bignell A, Bjartling C, Clark L, Cutcliffe LT, Lambden PR: Co-evolution of genomes 
and plasmids within Chlamydia trachomatis and the emergence in Sweden of a new variant strain. BMC Genomics 2009, 10(1):239-249.

65. Stephens RS, Kalman S, Lammel C, Fan J, Marathe R, Aravind L, Mitchell W, Olinger L, Tatusov RL, Zhao Q: Genome sequence of an obligate intracellular pathogen of humans: Chlamydia trachomatis. Science 1998, 282(5389):754.

66. Thomson NR, Holden MTG, Carder C, Lennard N, Lockey SJ, Marsh P, Skipp P, O'Connor CD, Goodhead I, Norbertzcak H: Chlamydia trachomatis: Genome sequence analysis of lymphogranuloma venereum isolates. Genome Res 2008, 18(1):161-171.

doi:10.1186/1471-2180-11-77

Cite this article as: Marsh et al:: Novel molecular markers of Chlamydia pecorum genetic diversity in the koala (Phascolarctos cinereus). BMC

Microbiology 2011 11:77.

Submit your next manuscript to BioMed Central and take full advantage of:

- Convenient online submission

- Thorough peer review

- No space constraints or color figure charges

- Immediate publication on acceptance

- Inclusion in PubMed, CAS, Scopus and Google Scholar

- Research which is freely available for redistribution

Submit your manuscript at www.biomedcentral.com/submit 